\title{
Erbil Citadel restoration: some thoughts on earth-built constructions exposed to seismic action
}

\author{
J. A. Martin-Caro \& I. Paniagua \\ INES Ingenieros, Spain
}

\begin{abstract}
Erbil Citadel Town is situated on top of an artificial, 32 metre high earthen mound, overlooking the sprawling modern city of Erbil. The city is believed to have been in continuous existence for 7,000 years or even longer. The Citadel is an ellipticalshaped town covering slightly more than 10 hectares of dense fabric, composed mainly of traditional courtyard houses, built in ochre-coloured bricks.

This paper will highlight the different studies for restoration work undertaken, paying special attention to the assessment of the structural performance of eight buildings of earthen construction under seismic action.

Keywords: earth construction, seismic action, restoration, world heritage, structural assessment, masonry structures.
\end{abstract}

\section{The Citadel of Erbil}

The city of Erbil is situated in the north-east of Iraq. Erbil is the capital of the autonomous Kurdish Region or Iraqi Kurdistan and is the headquarters of the Kurdish regional government. It is the third largest city in Iraq after Baghdad and Mosul, and is considered mankind's oldest continuously inhabited city.

Located eighty kilometres east of Mosul, Erbil is situated between the River $\mathrm{Zab}$ and Zab minor, tributaries of the Tigris. The province of Erbil is bordered to the north by Turkey and to the east by Iran and is the gateway city to the TaurusZagros mountain range [1].

The human settlement in Erbil is considered to be an antiquity with over 8,000 years of history. The city has been under the rule of many different peoples throughout its history, with all the civilizations present at some time or other in Erbil: Sumerians, Akkadians, Assyrians, Hittites, Babylonians, Achaemenids, 
Greeks, Parthians, Romans, Sassanids, Muslims, Timurids, Mongols, Ottomans and, more recently, the contemporary influence of the West.

Erbil (Arba'ilu) was a centre of communication in the Assyrian Empire and for centuries a meeting point on the crossroads of caravan routes linking East and West.

The historic city of Erbil consists of a circular mound of 30 metres high, covering a surface area of nearly $150,000 \mathrm{~m}^{2}$ and embankments between $35^{\circ}$ and $45^{\circ}$ (known archaeologically as Tells); the result of the accumulation of historical remains. This artificial elevation of incalculable archaeological wealth is topped by a Citadel, (Qelay or Qala't, meaning castle or Citadel), housing 322 groups of buildings, several palaces, four mosques and baths which date from the eighteenth century up to the present day.

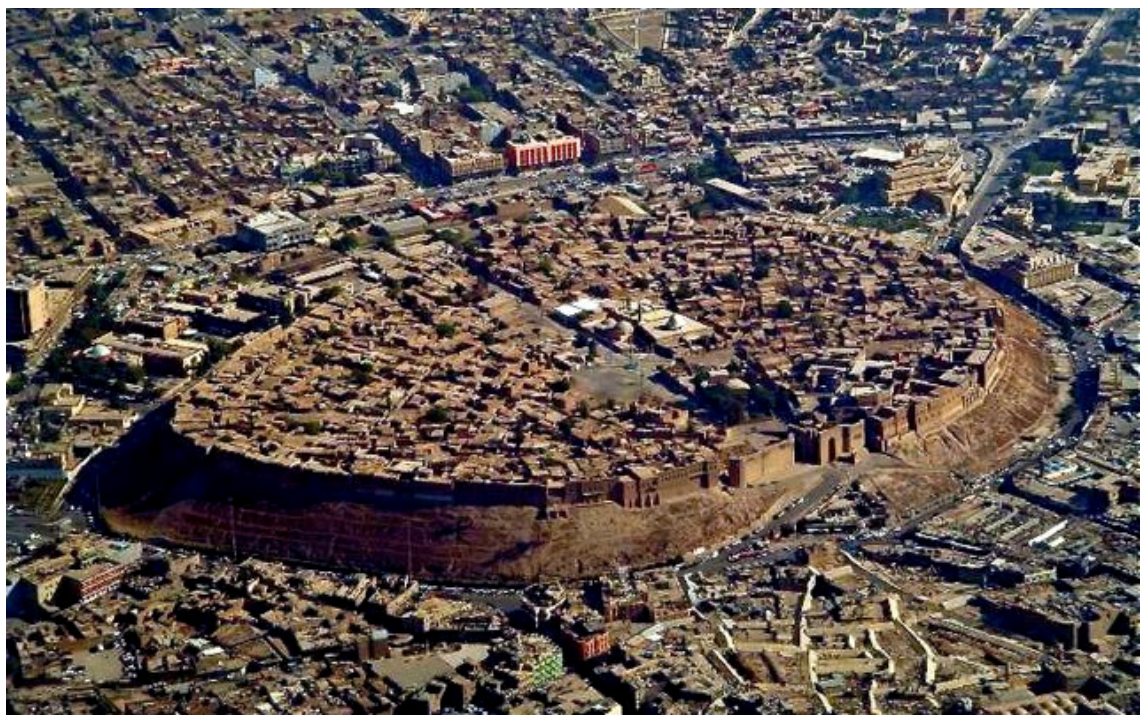

Figure 1: Aerial photo of the Citadel in 2012 [2].

In late 2007, with the passage of time, war, lack of maintenance and neglect after a period of 8,000 years of continuous history, the local authorities evicted the last Kurdish families (830) living in the Citadel and created the High Commission for the Restoration of the Citadel (HCERC) with UNESCO as an advisory partner.

From that moment began a period of analysis focussed on diagnosing the enormous and varying problems which had been identified in the Citadel. In this context come the specific studies of eight of the groups of edifications in the Citadel, intended to be a guide for the remainder.

\section{Issues involved}

In a project of this type there are a lot of constraints and variables that come into play in both the diagnosis and prescription of the remedial action to be taken. In 
this case, besides the usual conditions: historical, building, archaeological, architectural, economic, etc. of vital importance was the geotechnical behaviour of the Tell and the durability and resistance, in terms of behaviour, of earthworks under vertical and horizontal movement (mainly quakes).

As is customary, the first step was to identify exactly what architectural identity was to be restored. The definition of the image and appearance to be restored in in each building; in short, exactly what historical point in time, in terms of construction, was to be restored in each case, gave rise to a great deal of discussion.

To do this, the architectural research undertaken was focussed on assessing the remaining evidence of the Tell's original architecture and understanding the development of buildings and the changes over time. This has helped to explain what is original and why and, in turn, enabled us to establish the volume and distribution of the different "pieces" which are missing.
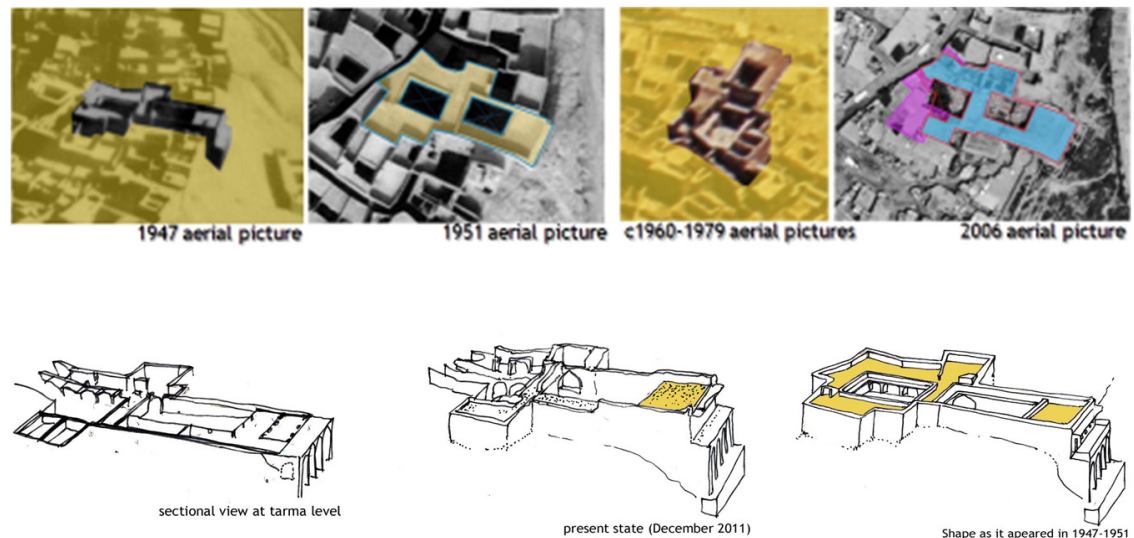

Figure 2: $\quad$ Models for reconstruction of group 1.

This research was based on the various different aerial photographs, drawings and ancient texts [3], etc. available. In addition, other studies such as the characterisation of materials and the study of different construction techniques helped to date the buildings' different elements, identifying the importance of each and the different stages existing side by side in one same building complex.

Once this first step had been taken, the second question was how to approach the project. In this regard, two conditions stood out above the rest: the geotechnical behaviour of the Tell, and the resistance and durability of the actual construction of the buildings in the face of seismic activity, settling, and the stability of the buildings on the edge of the Tell.

Therefore, the materials and construction techniques used in building the earthen-based structural elements, the geotechnical features of the site, and the structural assessment of the effect of vertical and horizontal loads, were detailed in groundwork studies [4]. 


\section{Materials and construction techniques}

The materials found in buildings which were representative of the whole Citadel span an enormous rate of types of state and condition which could be summed up as follows:

- Walls. Consist of rows of solid bricks, arranged in wall pattern (with varying degrees of firing) on both sides, with no connection between alignments. The space that confines the brick panels ( 30 to $100 \mathrm{~cm}$ thick) is filled with adobe, pieces of brick and fragments of rock (of varying compaction).

- Foundations. Strip foundation consisting of small caissons filled with pieces of brick/edges/compacted gravel, cemented locally with concrete with depths rarely over $1.5 \mathrm{~m}$. The pillars are supported under isolated footings of a similar nature.

- Floor structure. Beams of different diameters supporting sticks of an irregular length, as a joist. On top of these appears a mix of palm leaves, straw and/or wattle beneath the adobe or concrete.

- Roofing. Flat roof made of layers of adobe $(\mathrm{e}=50 \mathrm{~cm})$ topped with brick parapets $(\mathrm{h}=1-1.5 \mathrm{~m})$ of mud plaster.

- Wall coverings. Adobe plastering (1 to $3 \mathrm{~cm}$ ) covered by coatings of lime and/or gypsum, depending.

- Decoration. Frescoes, tempera and oil, as per technique and base layer material. The different pictorial layers and polychrome paintings were dated by composition and stratigraphy studies.

A project was designed and run to classify the mechanical and durable properties of the materials that make up these elements (brick, filler mud and plastering) in order to define present state and damage; diagnose processes and prescribe, in each case, the remedial action needed and consistent with their behaviour, while respecting their construction type.

\section{Structural assessment}

The aim was therefore to restore a group of buildings where most had lost the entire second floor; the roof and many other elements, both inside and outside (stairways, outbuildings, etc.).

This restoration work had to be done from a new perspective: firstly, it did not seem feasible to be able to meet the different structural standards currently firstly, because there were none; and secondly because it did not seems logical to enforce the same conditions as for normal buildings on this type of structure, which comes under the classification of cultural heritage.

Secondly, the assumptions of behaviour that are usually made within the mechanics of continuous mediums do not apply to many of the elements of this type of construction (especially stonework or earth). This is particularly relevant when considering the response to horizontal stresses in general and seismic stresses in particular.

Thirdly, the problems which had been detected were of a complex structural geotechnical origin, so the two analyses had to overlap. 


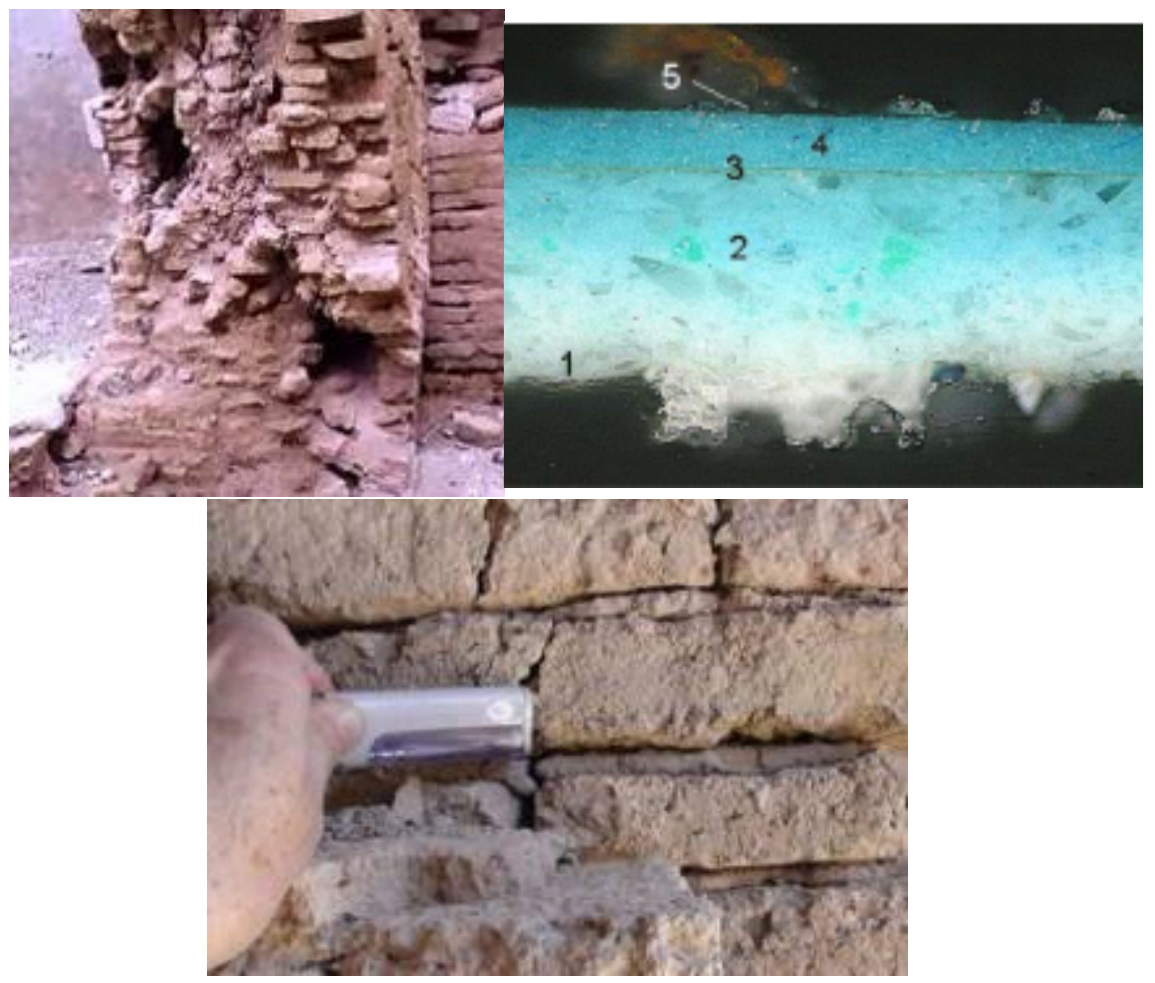

Figure 3: Photographs of different group 1 and 8 materials and photograph of a microscopic analysis to identify polychrome.

Therefore, the approach taken was originally aimed at understanding and diagnosing the damage detected, to then prescribe measures that could improve the structural behaviour of the whole, but without having to meet a safety level set by the regulations. The idea that governed the works was that of achieving adequate performance under normal loads (defining adequate as the nonappearance of damage, controlling the threshold values of variables) and providing the whole with additional resistance mechanisms for accidental events (earthquake).

\subsection{Building on top of centuries of archaeological fillings}

Geotechnical data from the geotechnical examination (drilling, electrical tomography and mechanical pits) interpret the Tell (mountain supporting the Citadel today) as being a chaotic heterogeneous filler (remains of brick, boulders, clay, sands in different proportions) of human origin, with little compaction, which reaches an average height of $30 \mathrm{~m}$.

Based on its nature and geological setting, it follows that:

- The Tell is especially sensitive to settling which occurs, given the effect of individual loads or transformations/reorganizations of fills due to the effect of 
water. This is considered to be a layer of minimum mechanical performance and potentially collapsible.

- $\quad$ The seismic effect. The Citadel is located in a medium to highly seismically active area (close to the Zagros mountain range) and to this must be added the contribution of the Tell when assessing the elastic response produced - and to be produced in the future - by horizontal accelerations on the buildings.

- The stability of the slopes has narrow limits: the configuration of embankments with slopes exceeding $1 \mathrm{H} / 1 \mathrm{~V}$ tends to produce rotational sliding. The various analyses undertaken indicate safety factors in the range of 1 for general landslides. Any changes in contours, furrows caused by runoff, and changes in humidity tend to trigger instability.

Moreover, the problem when proposing viable solutions to correct the damage detected was that it was not possible to project underpinning or land improvements due to; the type of construction to be underpinned; the length of slope instability which would require underpinning (due to having to cross the entire Tell); and the archaeological damage which could result. Therefore, it was decided to go ahead while accepting these conditioning factors, so that maximum settling was estimated under vertical loads and the weight and height of buildings was restricted. Foundations were tied and monolithed, ductility was added to the structures (see section below) and specific measures were prescribed for each building, designed to prevent the entry of water into the ground; prohibiting wells, and channeling surface runoff.

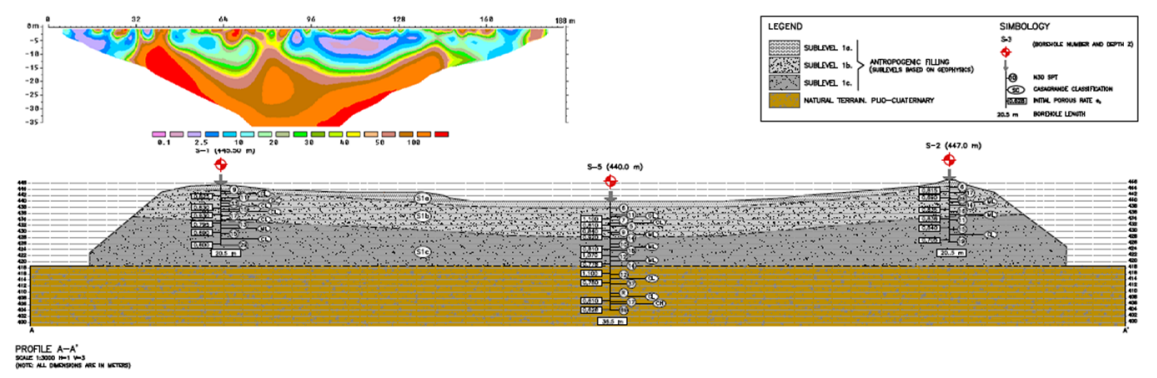

Figure 4: Photographs of electrical tomography and geotechnical Tell profile.

\subsection{Structural behaviour of earthen construction}

Having accepted the geotechnical risk, there were still two aspects that required deeper analysis: one of these was to try to improve the stability of the buildings on the edge of the Tell, subject to landslide problems caused by a steep slope and very susceptible to water; and the another: to try to improve the behaviour of these boxes, consisting of earthen walls, when exposed to earthquakes.

\subsubsection{Slope stability}

As indicated earlier, the embankments which make up the perimeter of the Tell had a delicate balance. To this fact was added the need for space over the last three centuries in the Citadel, which had led in some cases to new buildings being 
constructed on the edge of the embankment, even using the outer wall of the Tell as an inner wall. This had led to new buildings outside the original perimeter of the Citadel, resting directly on top of the embankment.

This new load configuration altered the already precarious balance of the embankment, causing further surface and local landslides in the area of the direct load and reducing even further, if possible, the safety levels of the general landslides.

As indicated, the application of load lines half-way down the embankment increases the emergence of local landslide that has been caused by the separation of the front elements of these buildings, a fact that could be corroborated during the inspection of these buildings.

From the analyses carried out (from the geotechnical data in the tests run and direct observation of stable geometries of existing embankments), it was found that while it is true that conventional safety limits could not be reached, overall behaviour could be improved via the following actions.

In buildings that were on the edge of the embankment, it was enough on the one hand, to protect the embankment to prevent erosion caused by water and, on the other hand, lighten the load on the facade near the edge of the embankment, and tie the front foundations up with the rest of the building.

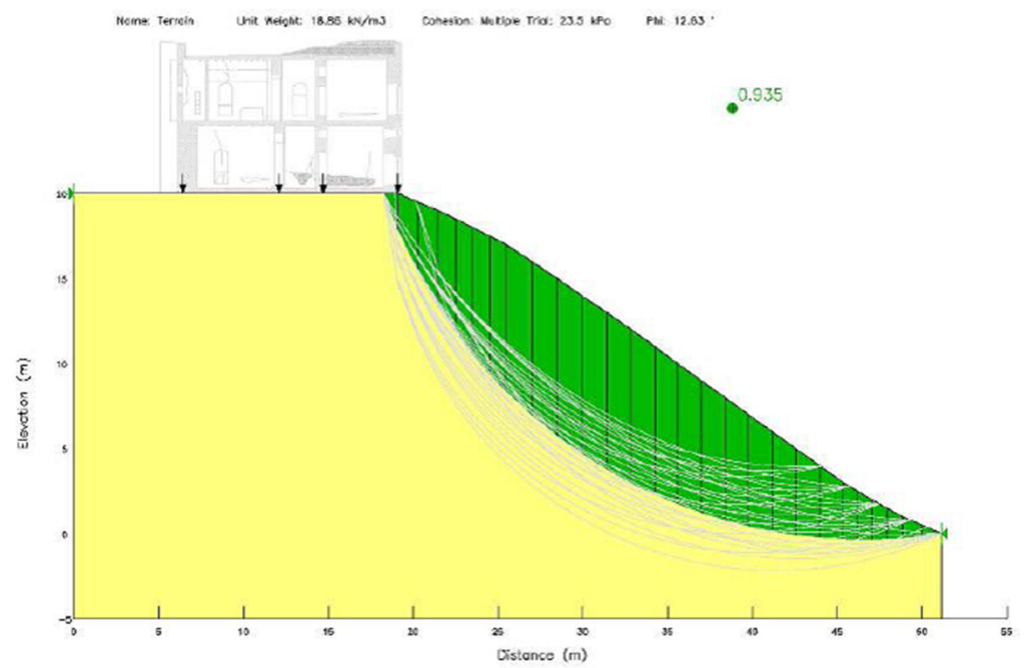

Figure 5: Study of the stability of the embankment in situations where the building is located on the edge. Safety factor 1 .

In the case of buildings positioned well within the embankment area, past action, though necessary, was not enough, since the likelihood of both general and local landslides occurring was very great.

Therefore, in these cases we studied the possibility of inserting a deep-seated underpinning line (with micropiles) on the front which would serve, on the one hand, to take vertical loads down to deeper strata, relieving the load completely 
from the embankment and, moreover, producing an anchor by slightly prestressing the micropiles/anchors, which would serve to pre-compress possible slippage circles. As this project could be potentially dangerous, since it could alter the internal construction of the Tell, it was agreed on a case-by-case basis with UNESCO and was only used in very special cases.
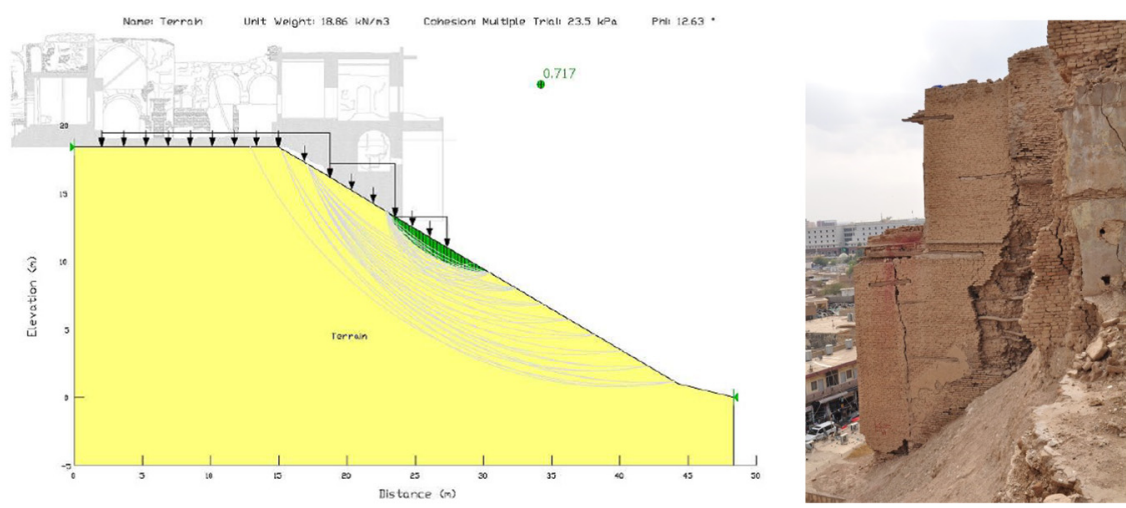

Figure 6: Study of the stability of the embankment in situations where the building is located within the confines of the embankment. Safety factor 0.7 .

\subsubsection{Seismic assessment}

First, it must be noted that the design of the buildings to be analysed did not fit within any of the usual seismic recommendations.

Floors were not symmetrical, not even on one axis: each building complex was made up of courtyards and annexes with different heights, without there being any consistent approach. In addition, extensions over time were identified where construction detail had not been observed; the walls had not been worked in their joins: the thickness, bonding and constitution of each wall was different (affecting local and overall rigidity), etc.

Moreover, the walls had no binding at the top, not even the construction detail of the support of the wooden floors led us to believe that these elements could act as a binding factor.

The shear strength of these walls was very small and their axial level did not help. It was thus decided that the strategy to follow to improve the resistant behaviour of these structures was that of substantially improving the shear strength of the masonry walls and providing the whole with greater ductility. Other possible improvements, such as providing the buildings with a certain symmetry at floor level was completely inviable for architectural reasons.

Jointly with UNESCO, it was agreed to accept the possibility of introducing new materials into the constructions, for which reason eventually wooden beams were prescribed at the tops of the walls, as a rigid framework to bind together the various different walls which, in turn, were connected with the continuous foundation by vertical elements. These vertical elements of fiberglass were housed 
in the interior filler of standard walls (sandwich with no strapping elements) and were anchored in the foundation and the upper wooden frame.
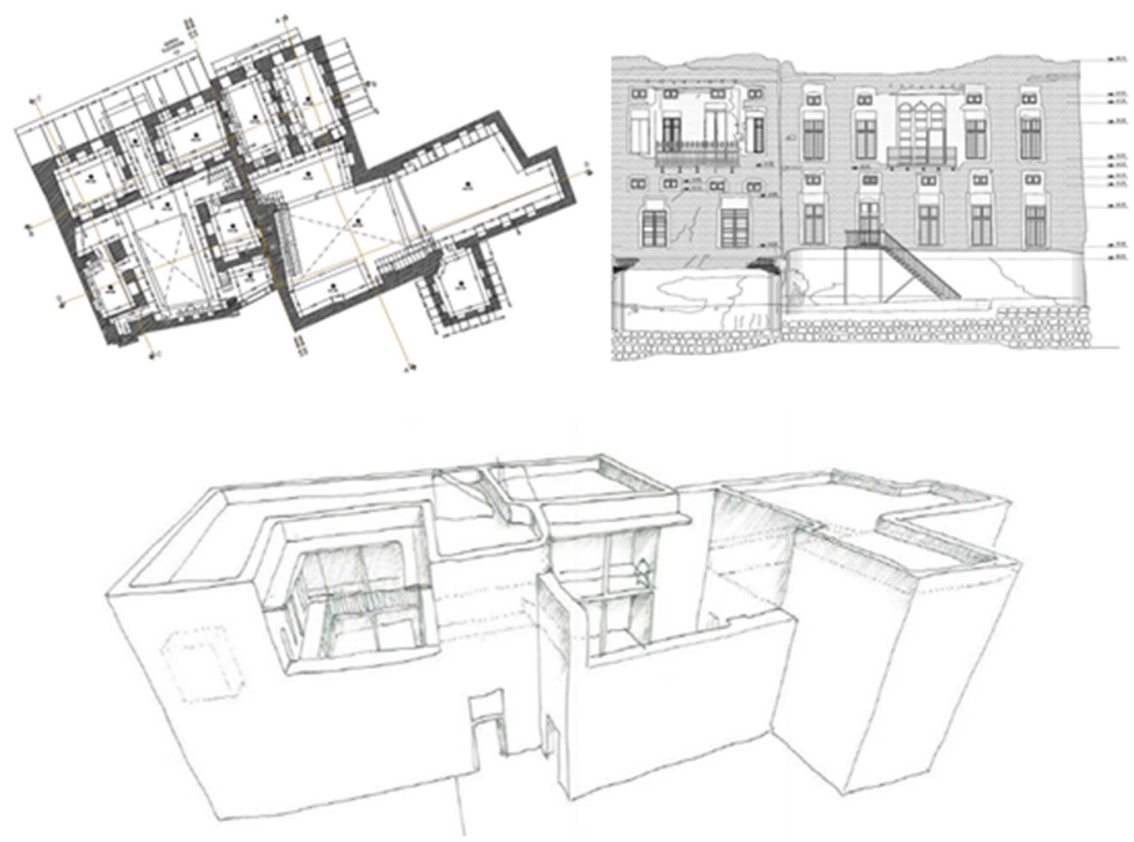

Figure 7: On flooring, elevations and 3D simulations of one of the buildings, the lack of symmetry can be seen.

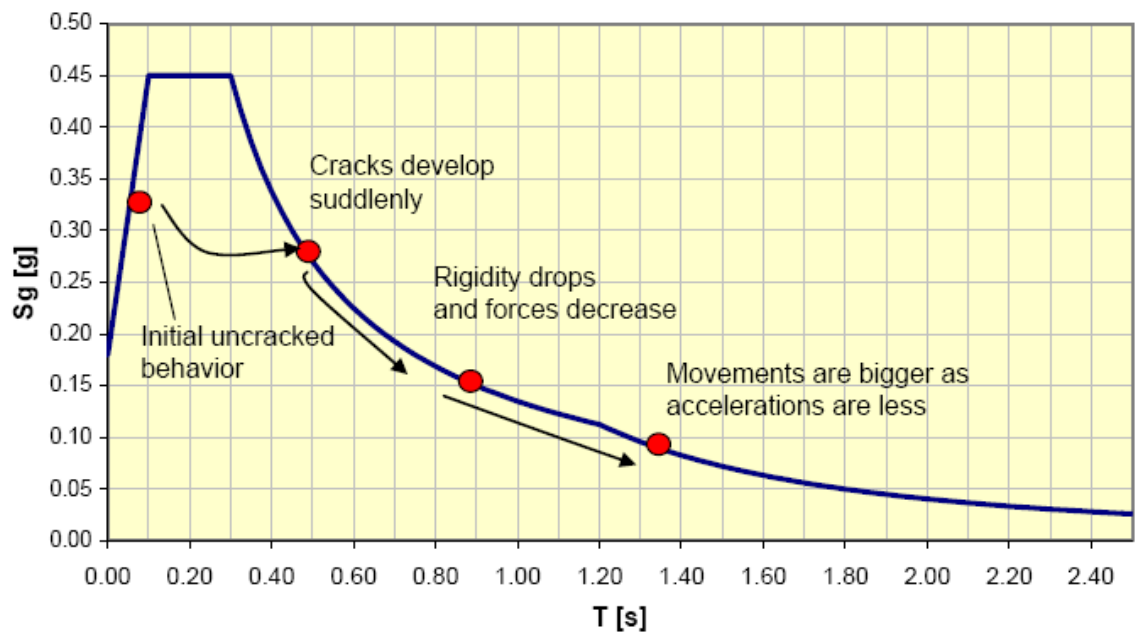

Figure 8: Outline of the seismic approach adopted in the design of the reinforcement. 
Finally, to enhance the shear strength of the walls it was decided to slightly prestress the vertical elements. Figure 9 shows a detail of the system. Thus, the level of pre-compression incorporated within the walls through a system of wooden wedges obtained an inside stress level close to $0.2 \mathrm{MPa}$ on both the lower and upper levels, providing a shear strength in the walls which was twice as high as before the works.

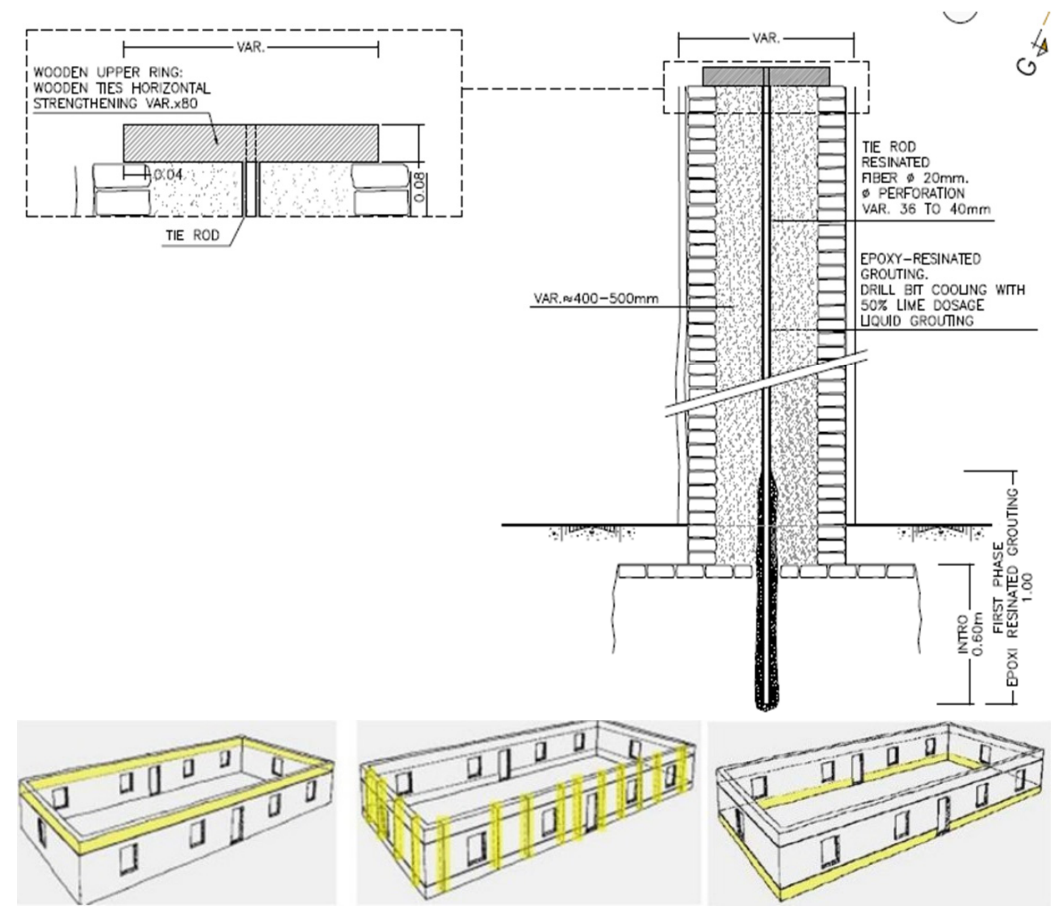

Figure 9: Detail of seismic reinforcement.

The feasibility of the proposal was tested out on site, performing tests where the grip level was tried out first on existing foundations, and the feasibility of using $40 \mathrm{~mm}$ drills. In addition, these vertical pre-stressing elements were repositioned to avoid coinciding with alcoves, narrowing walls, or other decorative elements.

Thus, the final structural configuration was based on a number of precompressed stretches of earthen or stonework walling, framed in a wooden structure, grounded in a continuous tied foundation.
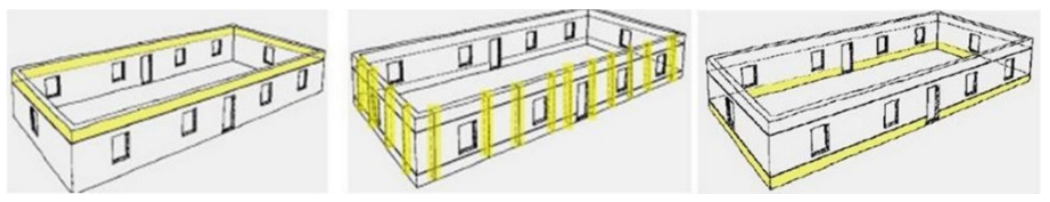

Figure 10: Detail of the plan envisaged. 


\section{Concluding remarks}

The buildings of the Citadel are in a critical condition. All have major damage, with total or partial collapse of the different rooms that make up each group of buildings. The need to restore these buildings without altering their appearance, or the materials used, has made it necessary to run a large number of studies which have reached the following conclusions:

- The structural elements comprising these structures cannot be considered as conventional resistive elements. The skeletal structure of these buildings consists of adobe walls covered with rows of brick without any binding elements or connections between stretches. All the elements in the structures, due to their poor characteristics and lack of maintenance, present a critical state of conservation.

- Conditions of the foundations. The buildings are supported upon 30 metres of filler, not compacted, chaotic in their composition, which gives the whole a low load bearing capacity (just enough to withstand the loads of a two-storey building), to which we must add their susceptibility to collapse due to changes in humidity and the dissolving and/or liquefying effect of seismic action. These conditions have led to general problems due to inadequate foundation associated with differential settling in all groups of buildings.

- We have conducted several studies that have analysed the phenomena of instability in buildings and the hillside. The slope is in a delicate balance which is compromised by the state of saturation of fillers and the additional and specific action of the loads of buildings on top of it. Without attempting to provide these structures with regulation safety standards, a series of actions have been planned that will improve their general and local stability.

- A system of seismic reinforcement has been designed for the load bearing walls so that without changing the geometry of buildings and using compatible materials, the structural ductility of the buildings as a whole increases and locally improves the cut-off capacity of the walls.

\section{References}

[1] Stevanovic, Z. and Iurkiewicz, A.A. (2009), Groundwater management in northern Iraq. Hydrogeology Journal, 17, pp. 367-378.

[2] UNESCO. Aerial photograph of the Citadel, 1933.

[3] Rich, C.J. ed. by his widow, Narrative on a residence in Kurdistan, on the site of ancient Nineveh; with the journal of a voyage down the Tigris to Bagdad and an account of a visit to Shirauz and Persepolis. 1820.

[4] INES. Studies for the conservation and restoration of eight building groups at the Erbil Citadel. Unpublished. (2012). 